\title{
Reasearch on Hardness and Fracture Toughness of 45 Steel before and after Hydrogen Sulfide Corrosion
}

\author{
Yanfei Sun ${ }^{1, a, *}$, Jing Wang ${ }^{1, b}$ \\ ${ }^{1}$ Beijing University of Technology, Beijing, PR China. \\ ${ }^{2}$ Beijing University of Technology, Beijing, PR China. \\ a sunyanfeijason@163.com, ${ }^{\mathrm{b}}$ wjing@bjut.edu.cn \\ *corresponding author
}

Keywords: Fracture Toughness; Corrosion; Fatigue.

\begin{abstract}
The fracture toughness of No.45 steel before and after corrosion is studied in this paper.Two experiments have been carried out about hardness experiment and COD experiment before and after corrosion. And the influence of corrosion condition of the hardness increment and fracture toughness is analyzed here. From the hardness test, we find that the hardness of No.45 steel rise at first and then fall down to the original hardness, and the maximum increment of No.45 steel is 21.From the COD experiment, we find that the stress intensity factor of No.45 steel before and after corrosion are $190.7 \mathrm{Mpam}^{1 / 2}$ and 149.8 $\mathrm{Mpam}^{1 / 2}$ respectively while their corresponding average stress of crack tip are $1076 \mathrm{Mpa}$ and $845.6 \mathrm{Mpa}$.It can be seen that hydrogen sulfide corrosion increases the brittle facture sensitivity of 45 steel, reduces the fracture toughness, and produces crack tip stress of 230.5Mpa. When we take the hardness of the experimental results into the hardness - stress calibration formula, the hydrogen corrosion generates 239Mpa hydrogen stress. The results of experiment hardness experiment and COD experiment are less than $10 \%$ of the crack stress in the COD experiment, which proves that hydrogen corrosion will cause hydrogen stress and then lead to the decrease of fracture toughness.
\end{abstract}

\section{Introduction}

Hydrogen sulfide can cause hydrogen damage of steel and lead the material to brittle fracture. It can also lead to catastrophic accident of large petrochemical equipment. The reason is that the hydrogen corrosion reduce the performance of the material to a certain extent and then make the material fracture. Therefore, it is very important to study the fracture toughness of the material for predicting the reliability of petrochemical equipment.

In recent years, Swieczko-Zurek B [1] found the material surface hardness is higher than the internal hardness after soaking in the hydrogen sulfide corrosion. Zhao Jingwei [2] other researches showed that there was a certain relationship between the hydrogen content and hardness, and put forward corresponding formulas for different materials. M Martin[3] had a new discovery of the hydrogen damage mechanism. He used scanning electron microscopy and atomic force microscopy to study the degree of hydrogen damage of different materials under different loads. It was found that there is a common property that the plastic deformation occurred before cracking and hydrogen accelerate the plastic deformation. 
There are two experiments in the paper. The first experiment uses the No.45 steel as object of the study in order to obtain the hardness increment along the depth after 96h soaked in corrosive environment and the hydrogen sulfide concentration is 1700ppm Combining the hardness-stress calibration formula. Then, the COD experiments of No.45 steel before and after 96h soaked in $1700 \mathrm{ppm}$ corrosive environment were carried out to obtain resistance curves, as well as the fracture toughness $\delta_{0.2 \mathrm{BL}}$. Finally it proves that hydrogen corrosion will cause the hydrogen-induced stress and leads to the decrease of fracture toughness.

\section{Experiment Method}

\subsection{Experiment material}

No.45 steel is used in this paper. The mechanical properties of the material are shown in Table 1.

Table 1 The mechanical properties of the material

\begin{tabular}{cccc}
\hline$E / \mathrm{GPa}$ & $R_{\mathrm{m}} / \mathrm{MPa}$ & $R_{\mathrm{P} 0.2} / \mathrm{MPa}$ & Poisson's ratio \\
\hline 210.0 & 744.0 & 437.6 & 0.3
\end{tabular}

\subsection{Specimen}

\subsubsection{Specimen for hardness test}

No.45 steel is selected as the experiment, the diameter is $18 \mathrm{~mm}$ while the height is $12 \mathrm{~mm}$.

\subsubsection{The specimen form of fracture toughness experiment}

According to GB/T 21143-2007[4] "Standard test method for static fracture toughness of metallic materials” to design the sample, three-point bend specimen is selected in this paper. Based on the requirement of the standard, sample thickness $B=10 \mathrm{~mm}$, sample width $W=20 \mathrm{~mm}$, span $\mathrm{S}=80 \mathrm{~mm}$.

According to the standard requirements, the specimen was pre-cracked by using high frequency fatigue testing machine, the maximum fatigue load is $14.87 \mathrm{kN}$, the stress ratio $\mathrm{R}=0.1$, and the length of fatigue crack length is $1.5 \mathrm{~mm}$.

\subsection{Experimental environment}

The hardness experiment after hydrogen sulfide corrosion and the fracture toughness test before and after hydrogen sulfide corrosion are carried out in the paper. according to NACE[5], standard A solution is used in this paper. This solution consisted of $5.0 \mathrm{wt} \%$ sodium chloride and $0.5 \mathrm{wt} \%$ glacial acetic dissolved in distilled water, and the H2S concentration of the solution should be saturated. Corrosion time is 96 hours. After the specified corrosion time has been reached, the specimen is removed from the corrosive environment, wiped, and the relevant experiments are carried out in the air. 


\subsection{Experimental environment}

\subsubsection{Hardness experiments of No.45 steel in hydrogen corrosion environment.}

In order to obtain the distribution of hardness along the depth of the cylinder specimen in the hydrogen corrosion environment, we adopted the method of peeling method. The Zwick Roell Z2.5 hardness tester is used in hardness test and Vickers hardness HV0.2 is considered as a test indicator. GB / T4340.1-1999 metal Vickers hard test[5] Part 1” is selected as the test standad, and loading time is $8 \mathrm{~s}$, holding time is $15 \mathrm{~s}$, maximum test load is $1.961 \mathrm{~N}$, unloading time is $4 \mathrm{~s}$.

\subsubsection{Hardness experiments of No.45 steel in hydrogen corrosion environment.}

According to GB/T 21143-2007 "Standard Test Method for static fracture toughness of metallic materials"[4] , multi-sample method is used for the fracture toughness experiments. Specimen was loaded and the crack opening displacement was measured by a clip gage. when the displacement reached to a certain value , unload the specimen and the force-displacement curve was recorded. And these samples were broken after frozen by liquid nitrogen. The original crack propagation length $\mathrm{a}_{0}$ and the final crack expansion amount $\Delta \mathrm{a}$ are measured and the crack tip opening displacement $\delta$ is calculated.

For a three-point bending specimen, $\delta$ is calculated as follows:

$$
\begin{gathered}
\delta=\left[\left(\frac{S}{W}\right) \frac{F}{\left(B B_{N} W\right)} \times g_{1}\left(\frac{a_{0}}{W}\right)\right]^{2}\left[\frac{\left(1-v^{2}\right)}{2 R_{p 0.2} E}\right]+\frac{0.6 \Delta a+0.4\left(W-a_{0}\right) V_{p}}{0.6\left(a_{0}+\Delta a\right)+0.4 W+Z} \\
g_{1}\left(\frac{a_{0}}{W}\right)=\frac{3\left(\frac{a_{0}}{W}\right)\left[1.99-\left(\frac{a_{0}}{W}\right)\left(1-\frac{a_{0}}{W}\right)\left(2.15-\frac{3.93 a_{0}}{W}-\frac{2.7 a_{0}^{2}}{W^{2}}\right)\right]}{2\left(1+\frac{2 a_{0}}{W}\right)\left(1-\frac{a_{0}}{W}\right)^{1.5}}
\end{gathered}
$$

The validity of $\delta_{0.2 \mathrm{BL}}$ is validated with the following conditions: 1 ) There is at least one data point between $0.10 \mathrm{~mm}$ and $0.30 \mathrm{~mm}$ passivation line bias lines while there are at least two data points between $0.10 \mathrm{~mm}$ and $0.50 \mathrm{~mm}$ passivation line bias lines; 2) $\left.\delta_{0.2 \mathrm{BL}}<\delta_{\max }=\left(\mathrm{W}-\mathrm{a}_{0}\right) / 20 ; 3\right)$ $\delta_{0.2 \mathrm{BL}}$ satisfies: $1.87(\mathrm{Rm} / \mathrm{Rp} 0.2)>[2(\mathrm{~d} \delta / \mathrm{da})]_{0.2 \mathrm{BL}}$

If $\delta_{0.2 \mathrm{BL}}$ meets the above conditions, the result is the non-dimensional sensitive $\delta_{0.2 \mathrm{BL}}$.

\section{Experiment Method}

\subsection{Hardness test results}

The experimental data of hardness and hardness increment after 96h soaked in 1700ppm corrosive environment can be seen in Fig 1.The table shows that the hardness of the each specimen will increase up till the maximum and then decrease to the minimum. The maximum hardness increment in the three sets of specimens is 21 and the minimum is -4 . 


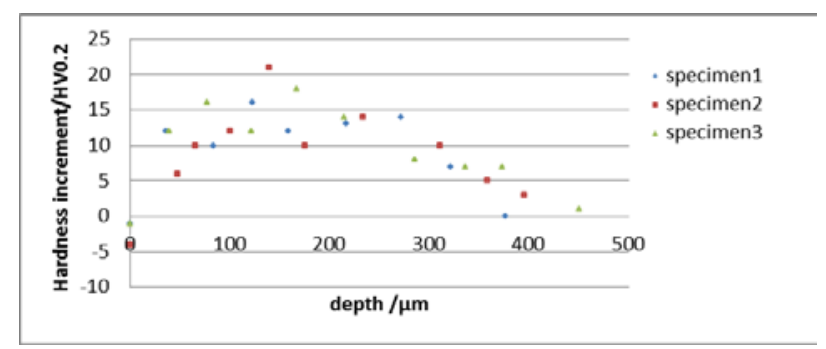

Figure 1 1700ppm hardness increment along the depth direction

\subsection{Fracture Toughness Experiment Results and Validity Judgment}

The $\delta-\Delta \mathrm{a}$ resistance curve and the fracture toughness $\delta_{0.2 \mathrm{BL}}$ test is conducted in the paper.According to the three-parameter index equation recommended in the national standard, the resistance curve and the fracture toughness are obtaioned.

non-corroded: $\delta=0.00059+0.2657 \Delta \mathrm{a}^{0.5010}$; corroded: $\delta=0.00104+0.20938 \Delta \mathrm{a}^{0.65243}$

$\delta_{0.2 \mathrm{BL}}$ is obtained before and after the corrosion And the distribution of the data points and the validity of the data are shown in Fig. 2 . The fracture toughness $\delta_{0.2 \mathrm{BL}}$ of the stabilized crack growth under the two experimental conditions are $0.131 \mathrm{~mm}$ (non-corrosive) and $0.080 \mathrm{~mm}$ (after corrosion of hydrogen sulfide).

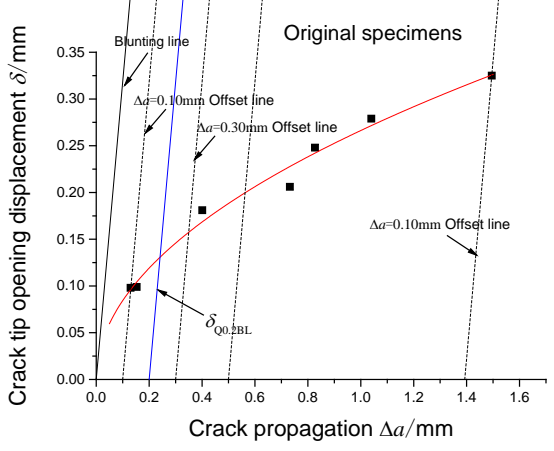

(a) original specimens

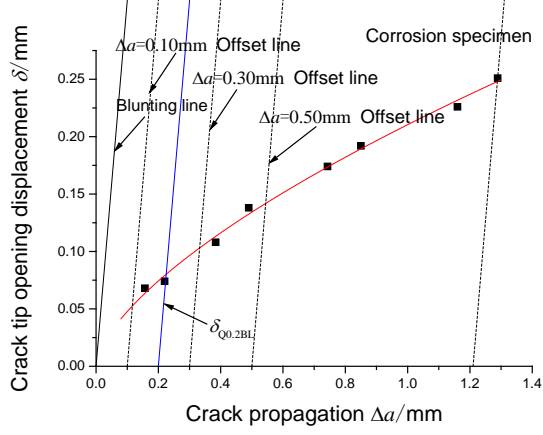

(b) corroosion specimens

Figure 2 The value of $\delta 0.2 \mathrm{BL}$ and validity judgment of original specimens and saturated $\mathrm{H} 2 \mathrm{~S}$ corroded specimens

\section{Analysis and discussion}

\subsection{The hardness analysis of $\mathbf{4 5}$ steel under hydrogen corrosion}

According to the results of hardness test, the hardness of the specimen corroded will increase at first and then decrease Therefore, the impact layer of No. 45 steel are divided into 3 layers. The first layer is the corrosion layer caused by hydrogen sulfide corrosion. The second layer is the impact of hydrogen embrittlement. The third layer which is not affected by corrosion is the parent material which is the part. Suresh S, Giannakopoulos A E[6] paper shows the relationship between hardness and compressive stress as:

$$
\sigma_{\text {compress }}=\left(1-\frac{H V}{H V_{b}}\right) \cdot \frac{P_{\max }}{A_{\mathrm{b}}} \cdot \frac{1}{\sin \alpha}=\left(1-\frac{219}{198}\right) \cdot \frac{1.961}{9.36 \times 10^{-4}} \cdot \frac{1}{0.927}=-239 \mathrm{Mpa}
$$

So the hardness increment is equivalent to produce 239Mpa stress. 


\subsection{Analysis and Discussion on fracture toughness}

$\delta_{0.2 \mathrm{BL}}$ is indicates the ability to resist crack initiation of the material. The test results show that $\delta_{0.2 \mathrm{BL}}$ is $0.131 \mathrm{~mm}$ and $0.08 \mathrm{~mm}$ before and after the corrosion of hydrogen sulfide. There are differences of 1.64 times between them. It can be seen that hydrogen sulfide corrosion reduces the fracture toughness of the material significantly.

\subsection{Conversion relationship between $\delta$ and $\mathrm{K}$}

The crack opening displacement $\delta$ and the stress field at the crack tip have a certain relationship. For the crack tip stress field, stress intensity factor $\mathrm{K}$ is a physical quantity to describe the electric field, critical stress intensity factor $\mathrm{K}_{\mathrm{IC}}$ is the minimum stress intensity factor of crack growth and it is an important parameter to measure fracture toughness of materials. In Engineering, the critical stress intensity factor $\mathrm{K}_{\mathrm{IC}}$ can be estimated by the crack initiation toughness $\delta_{0.2 \mathrm{BL}}$.

In the unified test method for fracture toughness[7-8], we have:

$$
\delta=\frac{J}{m \cdot \sigma_{\mathrm{y}}}
$$

while: $\delta$ : Crack tip opening displacement; $\mathrm{J}$ : experimental equivalent of $\mathrm{J}$ integral; $\sigma_{\mathrm{y}}$ : yield strength; m: reduction factor of COD

The relationship between $\mathrm{J}$ and $\mathrm{K}$ :

$$
J_{\mathrm{IC}}=\frac{K_{\mathrm{IC}}^{2}}{E^{\prime}}
$$

while: $K_{I C}$ : strain $K_{I C}$ fracture toughness of the plane; $E^{\prime}=\frac{E}{1-\mu^{2}} ; \mu$ : poisson ratio E: Elastic modulus. From formula(4) (5), we can obtain:

$$
K_{\mathrm{IC}}=\sqrt{\frac{m \cdot \delta_{0.2 \mathrm{BL}} \cdot \sigma_{y} \cdot E}{1-\mu^{2}}}
$$

The mechanical parameters of the material and the measured values of $\delta_{0.2 \mathrm{BL}}$ before and after the corrosion of hydrogen sulfide are respectively introduced into the (6). Then we get: before corrosion: $K_{\mathrm{IC}}=190.7 \mathrm{MPa} \sqrt{\mathrm{m}}$; after corrosion: $K_{\mathrm{IC}}=149.8 \mathrm{MPa} \sqrt{\mathrm{m}}$ It can seen that the critical stress intensity factor $\mathrm{K}_{\mathrm{IC}}$ of NO.45 steel before corrosion is about 1.27 times higher than that after corrosion. The result indicates that hydrogen sulfide corrosion increases the brittle fracture susceptibility and decreases the fracture toughness. The literature ${ }^{[9]}$ shows: the critical stress intensity factor $\mathrm{K}_{\mathrm{IC}}$ in air is 1.63 times higher than that in a hydrogen sulfide environment. Also conclusion that hydrogen sulfide corrosion reduces fracture toughness of metallic materials.

\subsection{The relationship between $\mathbf{K}$ and the average stress field of crack tip}

According to the conversion relations of (5) and (6), the corresponding stress intensity factor $\mathrm{K}=\mathrm{K}_{\mathrm{IC}}$ can be obtained.The stress intensity factor $\mathrm{K}$ of the crack tip and the nominal stress $\sigma$ of the crack tip have the relationship: (7):

$$
K_{\mathrm{I}}=Y \sigma \sqrt{\pi a}
$$

$Y$ is the shape factor, which is related to the size and position of the crack; $\sigma$ is the nominal stress; 
and $a$ is the crack size.From equation (7), we then obtain formula (9):

In the air, type (9):

$$
\sigma_{\text {air }}=K_{\mathrm{II} \mid \mathrm{air}} / \sqrt{\pi a}=190.7 / \sqrt{3.14 \times 0.01}=1076.1 \mathrm{MPa}
$$

$\mathrm{H}_{2} \mathrm{~S}$ corrosion, the formula (10):

$$
\sigma_{\mathrm{H}_{2} \mathrm{~S}}=K_{\mathrm{H}_{2} \mathrm{~S}} / \sqrt{\pi a}=149.8 / \sqrt{3.14 \times 0.01}=845.6 \mathrm{MPa}
$$

It can be seen from the formulas (9) and (10) that the nominal stress at the crack tip is 1076.1MPa and $845.6 \mathrm{Mpa}$ in the air and after corrosion. The difference between stress is $230.5 \mathrm{MPa}$.

\subsection{Validation of hydrogen stress}

From 3.1, it can be seen that the maximum hardness increment of hydrogen induced hardening layer will be 21 after the hydrogen sulfide corrosion of $1700 \mathrm{ppm}$ concentration for $96 \mathrm{~h}$, which is equivalent to produce 230.5Mpa hydrogen stress. From 3.5, it can be seen that the nominal stress of crack tip is 1076.1MPa.The difference between hardness calibration of the hydrogen stress and COD test conversion of the average crack stress is less than $10 \%$.

\section{Conclusions}

1). When No. 45 steel is soaked in hydrogen sulfide corrosion solution for different time, the hardness value will increase because of the effect of hydrogen embrittlement. The hardness increment value equals 239Mpa stress value.

2). The fracture toughness test shows that the hydrogen sulfide corrosion increases the brittlefracture susceptibility of No. 45 steel, decreases the fracture toughness, and induced 230.5MPa hydrogen stress on the material.

3). By comparing the two groups of experiments, it can conclude that the hydrogen corrosion will cause the additional stress on the No. 45 steel. This stress is hydrogen-induced stress.We hope you find the information in this template useful in the preparation of your submission.

\section{Acknowledgements}

This study was supported by National Science Foundation for Distinguished Young Scholars of China (11302007) and National key research and development program (2016YFC0801905-16).

\section{References}

[1] Swieczko - Zurek B, Zielinski A, Lunarska E. Hydrogen degradation of structural steels in technical hydrocarbon liquids [J]. Mater Corros. 2008;59(4):289-295

[2] H W Xiao, J W Zhao, W J Zhao, D Song, G Du, H Ding, Y Q Wang. Influence of Hydrogenation on Microstructure and Hardness of Ti6Al4V Alloy. Rare Metal Materials and Engineering, 2008, 37(10): 1795-1799

[3] M Martin. A new approach to discovering the fundamental mechanisms of hydrogen failure.

[4] GB/T 21143 - 2007, Metallic materials-Unified method of test for determination of quasistatic fracture toughness.

[5] NACE MR0175 -97, Sulfide Stress Cracking Resistant Metallic Materials For Oilfield Equipment, 1997. 
[6] Suresh S, Giannakopoulos A E. A new method for estimating residual stress by instrumented sharp indentation. Acta Materialia, 1998, 46 (16): 5755-5767.

[7] CHEN Chi, CAI Qigong, WANG Renzhi, Engineering Fracture Mechanics, (Bei Jing, National Defence Industry Press, 1977) p.331-332

[8] LI Qingfen, Fracture mechanics and the engineering application (Harbin: Harbin Engineering University Press, 2007) p. 43. 